\title{
Low temperature growth technique for nanocrystalline cuprous oxide thin films using microwave plasma oxidation of copper
}

\author{
K. V. Rajani a ${ }^{*}$, S. Daniels ${ }^{a}$, E. McGlynn ${ }^{b}$, R. P. Gandhiramanc, R. Groarke ${ }^{d}$ and P. J. McNallye \\ ${ }^{a}$ School of Electronic Engineering and NCPST, Dublin City University, Dublin 9, Ireland \\ ${ }^{b}$ School of Physical Sciences and NCPST, Dublin City University, Dublin 9, Ireland \\ ${ }^{c}$ BDI, Dublin City University, Dublin 9, Ireland
}

${ }^{d}$ School of Chemical Sciences, Dublin City University, Dublin 9, Ireland

${ }^{e}$ School of Electronic Engineering, Dublin City University, Dublin 9, Ireland

\section{ABSTRACT}

We report on the direct formation of phase pure nanocrystalline cuprous oxide $\left(\mathrm{Cu}_{2} \mathrm{O}\right)$ film with band gap $\sim 2 \mathrm{eV}$ by microwave plasma oxidation of pulsed dc magnetron sputtered $\mathrm{Cu}$ films and the highly controlled oxidation of $\mathrm{Cu}$ in to $\mathrm{Cu}_{2} \mathrm{O}$ and $\mathrm{CuO}$ phases by controlling the plasma exposure time. The structural, morphological and optoelectronic properties of the films were investigated. p-type $\mathrm{Cu}_{2} \mathrm{O}$ film with a grain size $\sim 20-30 \mathrm{~nm}$, resistivity of $\sim 66 \Omega \mathrm{cm}$ and a hole concentration of $\sim 2 \times 10^{17} \mathrm{~cm}^{-3}$ is obtained for a plasma exposure time of 10 min without using any foreign dopants. The optical absorption coefficient $\left(\sim 10^{5} \mathrm{~cm}^{-1}\right)$ of the $\mathrm{Cu}_{2} \mathrm{O}$ film is also reported.

Keywords: semiconductors, solar energy materials, oxidation

${ }^{*}$ Corresponding author. e-mail: kv.rajani2@ mail.dcu.ie, Tel: +353 1700 5872, Fax: +3531700 5508

\section{Introduction}

Cuprous oxide $\left(\mathrm{Cu}_{2} \mathrm{O}\right)$ is a naturally p-type, direct band gap $(\sim 2 \mathrm{eV})$, nontoxic metal oxide semiconductor material possessing a fairly high absorption coefficient in the visible region, with potential applications in solar energy conversion, catalysis and lithium ion batteries [1-2]. In addition, the $\mathrm{Cu}_{2} \mathrm{O}$ and $\mathrm{CuO}$ nanosystems have great potential for photo-activated hydrogen production, a key solution for the clean and recyclable $\mathrm{H}_{2}$ energy. There are several reports on the growth, characterization and applications of copper 
oxides, however, the electrical characteristics of the copper oxide films are strongly influenced by the preparation methods [3]. There are numerous reports on the exploitation of $\mathrm{Cu}_{2} \mathrm{O}$ as an active layer for solar cells [4-5]. Even though it has a theoretical conversion efficiency of around $20 \%$, actual efficiencies reported so far are around $2 \%$ [6]. One of the possible reasons for the lower conversion efficiency is the higher series resistance of the fabricated solar cells. Hence the development of $\mathrm{Cu}_{2} \mathrm{O}$ material with lower resistivity is very important for the improvement of the power conversion efficiency of solar cells based on this material. Again, uniform nanocrystalline $\mathrm{Cu}_{2} \mathrm{O}$ films on appropriate substrates have interesting applications in the field of heterogeneous photocatalysis. Similarly, the applications of $\mathrm{CuO}$ in gas sensors and as anodes for organic light emitting diodes and lithium ion batteries are also reported [7-8].

Although $\mathrm{Cu}_{2} \mathrm{O}$ has several potential applications, it is difficult to produce phase pure $\mathrm{Cu}_{2} \mathrm{O}$ without traces of $\mathrm{CuO}$, which is an impediment for the semiconductor applications of this material. In this letter, we report on the use of a direct and simple processing technique for the low temperature deposition of phase pure $\mathrm{Cu}_{2} \mathrm{O}$ with nanocrystalline grains using microwave plasma oxidation of $\mathrm{Cu}$ films at $300^{\circ} \mathrm{C}$. The microwave plasma can provide an extremely high density of predominantly $\mathrm{O}^{-}$ions compared to the normal glow discharge. These ions can be implanted into the growing oxide films and cause high oxidation rate of the films [9]. The bombardment of energetic oxygen ions from the plasma produces a quick and uniform oxidation of the $\mathrm{Cu}$ films compared to the more conventional high temperature annealing methods without plasma, which thereby forms dense nanocrystalline phase pure $\mathrm{Cu}_{2} \mathrm{O}$ films with lower resistivity without the use of any extrinsic dopants. To the best of our knowledge this is the first report on the microwave plasma oxidation of $\mathrm{Cu}$ films to $\mathrm{Cu}_{2} \mathrm{O}$.

\section{Experimental}

$\mathrm{Cu}$ thin films of $80 \pm 5 \mathrm{~nm}$ thickness were deposited on glass substrates by pulsed dc magnetron sputtering of a Cu target (Kurt J Lesker; $99.99 \%$ pure). The base pressure of the sputtering chamber and the deposition pressure were $2 \times 10^{-6}$ mbar and $5.5 \times 10^{-3}$ mbar, respectively. The target was pre-sputtered for about 10 min and the distance between the target and the substrate was $6 \mathrm{~cm}$. The sputtering was carried out in pure argon atmosphere. The $\mathrm{Cu}$ films are then transferred in to a Hitachi microwave plasma chamber for oxygen plasma exposure, in which the sample holder was kept at a temperature of $300{ }^{\circ} \mathrm{C}$. Oxidation was performed in a 1000 sccm flow of oxygen. The chamber uses a microwave plasma with frequency and power of $2.45 \mathrm{GHz}$ and $600 \mathrm{~W}$ 
respectively. The $\mathrm{Cu}$ films are exposed to the oxygen plasma for different time intervals of 10, 20 and 30 minutes.

\section{Results and discussion}

Figure 1(a) shows the $\theta-2 \theta$ X-ray diffraction (XRD) patterns of the oxidized copper films prepared with various oxygen plasma exposure times, together with the data of the as-deposited (ASD) $\mathrm{Cu}$ film. The ASD sample clearly exhibits the presence of a $\mathrm{Cu}(111)$ peak. A complete formation of pure cubic $\mathrm{Cu}_{2} \mathrm{O}$ phase is verified from the XRD pattern of the 10 min plasma exposed film with the appearance of the $\mathrm{Cu}_{2} \mathrm{O}$ (111) and (200) peaks, with predominant orientation along the (111) direction and with no indication of other phases. These diffraction peaks are in good agreement with the standard $\mathrm{Cu}_{2} \mathrm{O}$ patterns [10]. The additional formation of the monoclinic $\mathrm{CuO}$ phase together with the $\mathrm{Cu}_{2} \mathrm{O}$ can be clearly seen in the XRD pattern of the films deposited at longer plasma exposures of 20 and $30 \mathrm{~min}$. Efficient oxidation of the $\mathrm{Cu}$ films at lower temperature could be due to the supply of the portion of the oxidation activation energy from the highly energetic plasma. The increase in the intensity of the $\mathrm{CuO}(111)$ and (002) peaks at higher plasma exposures (30 min) can be attributed to further oxidation of $\mathrm{Cu}_{2} \mathrm{O}$ to $\mathrm{CuO}$ by the consumption of more oxygen from the plasma, via the possible addition of more energy to the reaction process from the longer oxygen ion bombardment sufficient for the oxidation to $\mathrm{CuO}$. The oxidation of the $\mathrm{Cu}$ film is found to be highly controllable and the ratio of the two phases can be easily tuned by adjusting the plasma exposure time of the $\mathrm{Cu}$ films.

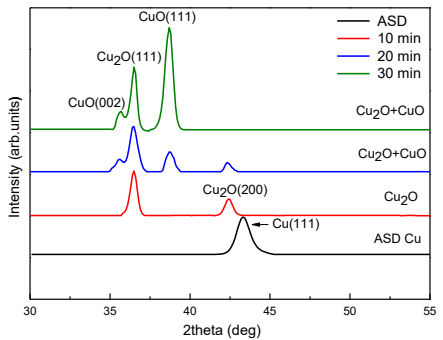

(a)

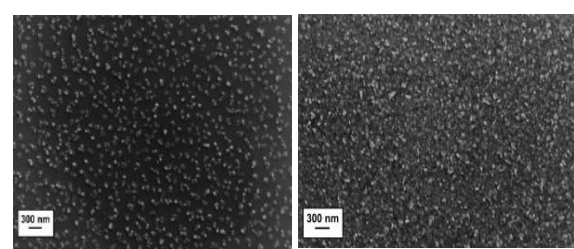

(b)

Fig.1. (a) XRD patterns of the ASD and oxygen plasma exposed $\mathrm{Cu}$ films. (b) SEM micrographs of the ASD Cu film (left) and $\mathrm{Cu}_{2} \mathrm{O}$ film (right) on glass substrates. 
The morphologies of the films were examined using scanning electron microscopy (SEM) analysis. Figure 1(b) shows the SEM images of the ASD film and the $\mathrm{Cu}_{2} \mathrm{O}$ film (10 min plasma exposed) with the same magnifications. The $\mathrm{Cu}$ film shows the presence of small grains of dimension of approx. $50 \mathrm{~nm}$. Interestingly, as the $\mathrm{Cu}$ is exposed to the oxygen plasma for $10 \mathrm{~min}$, densely packed grains of $\mathrm{Cu}_{2} \mathrm{O}$ of sizes around $20-30 \mathrm{~nm}$ are formed.

For short plasma treatment times the formation of the less thermodynamically stable $\mathrm{Cu}_{2} \mathrm{O}$ phase is the first stage of the oxidation. This is expected due to the relatively small amount of oxygen present for such short treatment times, and also due to the lower oxidation activation energy of the $\mathrm{Cu}_{2} \mathrm{O}$ phase [11]. While one might expect that even for short plasma treatments $\mathrm{CuO}$ islands would form in the $\mathrm{Cu}$ matrix, we believe that the greater surface energy effects at boundaries between oxidized and unoxidized $\mathrm{Cu}$ regions in such a case would tend to favour the formation in the first instance of larger $\mathrm{Cu}_{2} \mathrm{O}$ islands. It is also expected that the plasma could enhance both the diffusion of oxygen and the interfacial $\mathrm{Cu}$ oxidation rate. As plasma treatment times increase, the contribution towards the oxidation activation energy increases and the amount of oxygen present for reaction grows. The oxidized $\mathrm{Cu}$ can transform to the more thermodynamically stable $\mathrm{CuO}$ phase, with surface effects reduced as larger $\mathrm{CuO}$ islands are possible due to the larger amount of oxygen present. This explanation is consistent with our data shown above.

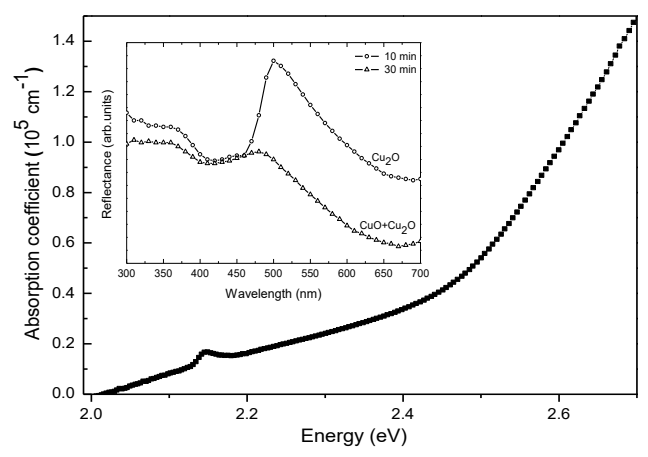

Fig.2. Absorption spectrum of $\mathrm{Cu}_{2} \mathrm{O}$ at $77 \mathrm{~K}$ and inset: Reflectance spectra of the phase pure $\mathrm{Cu}_{2} \mathrm{O}(10$ $\min )$ and $\mathrm{CuO}+\mathrm{Cu}_{2} \mathrm{O}(30 \mathrm{~min})$ films. 
Low temperature $(77 \mathrm{~K})$ absorption measurement was performed on the film in order to estimate the optical band gap of the $\mathrm{Cu}_{2} \mathrm{O}$ (figure 2). The spectrum shows the band edge at $2.01 \mathrm{eV}$, with the appearance of a small peak at $2.14 \mathrm{eV}$, which corresponds to the first allowed green excitonic peak of $\mathrm{Cu}_{2} \mathrm{O}$. These values are in close agreement with the previous reports on bulk $\mathrm{Cu}_{2} \mathrm{O}$ [12]. The presence of the $\mathrm{Cu}_{2} \mathrm{O}$ phase formed during the 10 min oxygen plasma exposure can be again verified using the reflectance spectra in the inset of figure 2 . The presence of the two peaks around $2.5 \mathrm{eV}$ and $2.7 \mathrm{eV}$ in the $\mathrm{Cu}_{2} \mathrm{O}$ sample can be observed from the reflectance spectra, which correspond to the direct allowed transitions to the $n=1$ exciton levels of the blue and violet series [13].

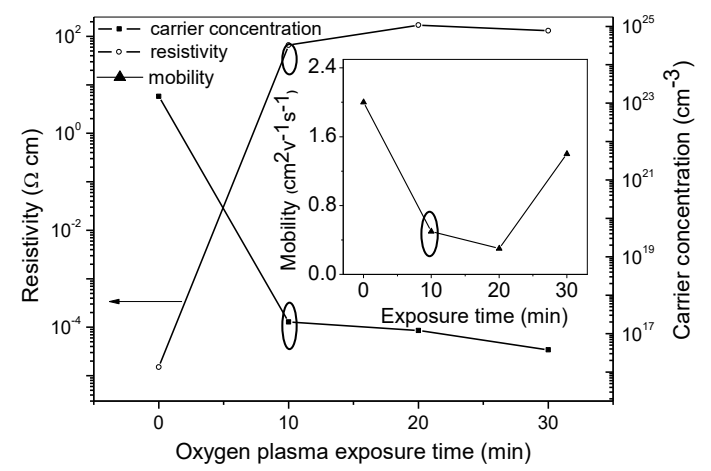

Fig.3. Variation of resistivity, carrier concentration and mobility (inset) plotted against the time of oxygen plasma exposure. The circled points correspond to the data of the $\mathrm{Cu}_{2} \mathrm{O}$ film.

The electrical properties of the oxidized copper films and ASD Cu were measured using Hall effect measurements and the data are plotted in figure 3. All oxidised copper films show p-type conductivity and ASD film shows n-type conductivity. The $\mathrm{Cu}_{2} \mathrm{O}$ film (10 min plasma exposed film) exhibited a resistivity and mobility of $\sim 66 \Omega \mathrm{cm}$ and $\sim 0.5 \mathrm{~cm}^{2} \mathrm{~V}^{-1} \mathrm{~s}^{-1}$, respectively, with p-type carrier concentration of $\sim 2 \times 10^{17} \mathrm{~cm}^{-3}$. The p-type conductivity is probably due to the presence of interstitial oxygen and negatively charged copper vacancies [14]. As the time of oxygen exposure increases to $20 \mathrm{~min}$, the film comprises of both $\mathrm{Cu}_{2} \mathrm{O}$ and $\mathrm{CuO}$ phases, with $\mathrm{Cu}_{2} \mathrm{O}$ as the dominant phase. The resistivity increases to $\sim 170 \Omega \mathrm{cm}$, with a lower mobility and carrier concentration of $\sim 0.3 \mathrm{~cm}^{2} \mathrm{~V}^{-1} \mathrm{~s}^{-1}$ and $\sim 1.2 \times 10^{17} \mathrm{~cm}^{-3}$, respectively. For the 30 min exposed sample, the dominant phase was $\mathrm{CuO}$, and the resistivity decreased to $\sim 130 \Omega \mathrm{cm}$ and the carrier concentration also decreased by one order of magnitude to a value of $\sim 3.8 \times 10^{16} \mathrm{~cm}^{-3}$. One of the possible reasons for the relatively higher carrier 
concentration $\left(\sim 10^{17} \mathrm{~cm}^{-3}\right)$ and hence a lower resistivity $(\sim 66 \Omega \mathrm{cm})$ for the pure $\mathrm{Cu}_{2} \mathrm{O}$ phase obtained by the present preparation method could be the increase in the presence of ionized copper vacancies as well as the densification of the film due to the bombardment by the oxygen species from the plasma. Furthermore, the lower mobility value of the pure $\mathrm{Cu}_{2} \mathrm{O}$ phase reported in the present work is attributed to the presence of increased grain boundary scattering due to the presence of nanocrystalline grains.

\section{Conclusion}

We have demonstrated a method for low temperature deposition of phase pure p-type nanocrystalline $\mathrm{Cu}_{2} \mathrm{O}$ thin films. $\mathrm{Cu}_{2} \mathrm{O}$ films with low resistivity could be a worthwhile candidate for photovoltaic applications. The present oxidation method has the additional advantage of excellent control over the rate of oxide formation of the oxides, which also could have interesting applications in heterogeneous catalysis.

\section{Acknowledgments}

This project was funded by the SFI Research Frontiers Programme, the Enterprise Ireland Commercialization Fund for Technology Development and partially supported by the Irish Higher Education Authority PRTLI "INSPIRE" project and the SFI "Precision" Strategic Research Cluster. The authors would like to thank Mr. Conor Murphy for his technical support.

\section{References}

[1] Bordiga S, Paze C, Berlier G, et al. Catal Today 2001;91:70.

[2] Bohannan EW, Shumsky MG, Switzer JA. Chem Mater 1999;2289:11.

[3] Pollack GP, Trivich D. J Appl Phys 1975;163:46.

[4] Rakhshani AE. Solid-State Electron 1986;7:29.

[5] Mittiga A, Salza E, Sarto F, et al. Appl Phys Lett 2006;163502:88.

[6] Yuhas BD, Yang P. J Am Chem Soc 2009;3756:131.

[7] Hu W, Manabe K, Furukawa T, et al. Appl Phys Lett 2002;2640;80.

[8] Mu Y, Yang J, Han S, et al. Mater Lett 2010;1287:64. 
[9] Ligenza JR. J Appl Phys 1965;2703:36.

[10] Yin M, Wu CK, Lou Y, et al. J Am Chem Soc 2005;9506:127.

[11] Wieder H, Czanderna AW. J Phys Chem 1962;816:66.

[12] Baumeister PW. Phys Rev 1961;359:121.

[13] Malerba C, Biccari F, Ricardo CLA, et al. Sol Energ Mater Sol Cells 2011;2848:95.

[14] Noaln M, Elliot SD. Phys Chem Chem Phys 2006;5350:8. 